\title{
Experimento de produção sobre a prosódia da não exaustividade no português brasileiro
}

\section{Daise Ribeiro Pereira Carpes}

Doutoranda em Linguística. Programa de PósGraduação em Linguística, Universidade Federal de Santa Catarina, Brasil.

daiseribeiro@gmail.com

\section{Izabel Christine Seara}

Doutora em Linguística. Departamento de Língua e Literatura Vernáculas, Universidade Federal de Santa Catarina, Brasil.

izabels@linse.ufsc.br

Resumo: Este artigo apresenta os primeiros resultados de uma pesquisa cujo objeto é a não exaustividade no PB. Pretendemos verificar se e como a prosódia, mais precisamente a entoação, direcionaria a interpretação do ouvinte diante de sentenças com foco não exaustivo, comparando suas curvas entoacionais com sentenças de focos exaustivo e contrastivo. Os primeiros resultados indicam que o foco não exaustivo pode ser marcado pela prosódia por meio de uma curva entoacional específica, e que as curvas com foco exaustivo ou contrastivo teriam um contorno entoacional muito semelhante e, por isso, precisariam de marcadores lexicais, como o 'só' e 0 'não'.

Palavras-chave: Prosódia; foco; não exaustividade
Juan Manuel Sosa

Doutor em Linguística. Simon Fraser University,

Canadá; Programa de Pós-Graduação em Linguística, Universidade Federal de Santa Catarina, Brasil. sosa@sfu.ca

Abstract: This article presents the initial findings of a study on non-exhaustivity in Brazilian Portuguese. We aim to verify if and how prosody, more specifically,intonation, can direct the interpretation by listeners exposed to utterances with non-exhaustive focus, comparing their intonational contours with those of utterances with exhaustive and contrastive focus. The first results show that non-exhaustive focus can be expressed prosodically by means of specific intonational contours, but also that the pitch curves with either exhaustive or contrastive focus seem to have a very similar intonational shape; for this reason the latter would need lexical markers like 'only' and 'not'.

Key-words: Prosody; focus; non-exhaustivity 



\section{Introdução}

Este estudo configura-se em um experimento inicial sobre a prosódia da não exaustividade semântica no português brasileiro $(\mathrm{PB})$.

O objetivo deste trabalho é analisar as curvas de $\mathrm{F}_{0}$ de sentenças com foco não exaustivo, comparandoas com as curvas de sentenças com foco exaustivo e contrastivo. Pretendemos verificar se a entoação serviria para direcionar a interpretação do ouvinte diante de uma sentença com foco não exaustivo, ou seja, se o foco não exaustivo é marcado por meio de uma curva entoacional específica, diferentemente dos outros dois focos aqui contrastados.

Nossa pergunta principal, então, é: a curva entoacional seria suficiente para marcar a não exaustividade, ou um elemento lexical seria imprescindível para a sua percepção por parte do interlocutor? Nossa hipótese é a de que o foco não exaustivo seria marcado pela prosódia, por meio de uma curva específica para esse caso. E uma segunda questão é colocada: os três tipos de foco aqui investigados teriam uma curva entoacional particular que os caracterizasse ou seria necessário o uso de um marcador lexical? Nossa hipótese é a de que haveria a necessidade de um marcador lexical para os focos contrastivo e exaustivo ("não" e "só", respectivamente).

Para apresentação dos dados deste estudo, na Seção 1, o referencial teórico que norteia a pesquisa; na Seção 2, a metodologia para a coleta dos dados; na Seção 3, a análise a discussão dos resultados e, as considerações finais.

\section{Os focos investigados}

O termo focoé usado para descrever proeminências prosódicas que servem a funções pragmáticas e semânticas (ROOTH, 1997), tais como veicular a informação não pressuposta na sentença (MORAES, 2006; 
QUAREZEMIN, 2009). Jackendoff (1972, apud KLEIN, 2003, p. 129-130) considera o foco "um traço semântico marcado na sintaxe cuja realização fonológica é o acento principal que se dá em todo o constituinte focalizado ou em um subconstituinte deste, conforme as regras de acento nuclear da língua em questão".

O foco é um recurso que o falante usa para dar destaque a um trecho do seu enunciado ao qual deseja que o ouvinte dê atenção especial (KLEIN, 2003; MENUZZI, 2012; QUAREZEMIN, 2009). Para Rooth (1997, p. 275), os falantes modificam "a forma da modelagem semântica das frases" para que, assim, essas frases com diferenças na localização do foco tenham diferentes valores semânticos. Sendo assim, o acento principal de uma sentença sempre cai sobre o elemento focalizado (QUAREZEMIN, 2009). Ainda, uma determinada afirmação não pode ter mais de um foco e uma dada proposição não pode expressar mais de uma afirmação (LAMBRECHT, 1994, p. 329).

"Foco" é definido como o elemento de uma proposição pragmaticamente estruturada cuja ocorrência torna possível para a frase expressar a "afirmação pragmática", ou seja, transmitir novas informações a um destinatário. Um pouco mais tecnicamente, o foco é o elemento pelo qual o pressuposto e a afirmação diferem um do outro. (LAMBRECHT, 2000, p. 612)

Há dois tipos de foco na literatura: foco amplo e foco estreito (FROTA, 2000). Quanto aos seus padrões de proeminência, o foco amplo receberia um acento não marcado (ou neutro), enquanto o foco estreito teria o acento marcado. Os três focos em análise neste trabalho são do tipo estreito (QUAREZEMIN, 2009).

Alguns autores, dentre eles Fintel (1994 apud OLIVEIRA e SEARA, 2012) e Büring (2007 apud OLIVEIRA e SEARA, 2012), acreditam que a prosódia 
seja um indício pragmático que sirva para direcionar uma interpretação, sem determiná-la semanticamente. Para Lambrecht (1994, apud POLINSKI, 1999), o acento da sentença seria uma instrução do falante para que o ouvinte estabeleça uma relação pragmática entre uma denotação e uma proposição. "Os elementos prosódicos servem para ponderar os valores semânticos dos enunciados, sendo uma das formas de que dispõe o falante para dizer a seu interlocutor como ele deve proceder diante do que ouve". (CAGLIARI, 2002, p. 43).

Sabe-se que o foco pode afetar o fraseamento prosódico, a proeminência e a entoação em várias línguas (FROTA, 2000). Os falantes utilizam algum tipo de marcador prosódico/melódico para fazer indicações aos seus interlocutores a respeito das entidades focadas nas sentenças que proferem. Então, além de a prosódia destacar o elemento focalizado na sentença, ela parece indicar o tipo de foco desse elemento. Para uma melhor compreensão, tomemos a situação em (1):

(1) (a) Maria chegou a MACEIÓ em outubro.

(b) Maria chegou a Maceió em OUTUBRO.

Se o acento prosódico incidir sobre Maceió (1a), a sentença veicula a informação de que Maria chegou a Maceió e não a outra cidade. Se, por outro lado, o acento estiver sobre outubro (1b), então a informação nova e focalizada será referente a quando Maria chegou. Os casos ilustrados em (1) podem representar foco exaustivo ou contrastivo. Isso porque não temos aqui o contexto em que essas frases foram enunciadas. O foco será exaustivo se a informação focalizada for nova no contexto conversacional. Tal foco ocorre, por exemplo, quando (1b) for resposta a uma pergunta como "Quando Maria chegou a Maceió?", pois a informação nova (outubro) está focalizada. Mas o foco poderá ser contrastivo se a 
informação focalizada estiver corrigindo uma informação dada pelo interlocutor. Por exemplo, corrigindo uma afirmação como "Maria chegou a Maceió em agosto". Ao proferir (1b), o falante estará retificando uma asserção de seu interlocutor.

Há uma relação entre o foco de uma sentença e o seu acento principal, que é também chamado de acento nuclear. Nesse caso, há uma proeminência do pitch (considerado o correlato acústico da frequência fundamental) nos constituintes focalizados. Qualquer que seja o tipo de foco, o constituinte focalizado da sentença deve conter a palavra com maior proeminência da frase (QUAREZEMIN, 2012).

Uma sentença com foco não exaustivo, objeto deste estudo, é aquela cuja proposição não é a única verdade para o que se está afirmando. Quando um falante oferece uma resposta não exaustiva a uma pergunta, ele não pode afirmar que outros possíveis candidatos a preencher essa variável são cancelados (ELORDIETA E IRURTZUN, 2010). A sua sentença informa que ele tem certeza da verdade de sua resposta, mas sem garantir que outras respostas não sejam possíveis, que não possam também preencher a variável em aberto. Vejamos um exemplo. Um falante enuncia (como resposta à pergunta "O que você comeu hoje no almoço?"):

(2) "Hoje eu almocei FILÉ MIGNON."

Com a sentença em (2), o falante não está necessariamente afirmando que comeu apenas filé mignon e mais nada. Ele certamente comeu outras coisas, mas quis destacar o filé mignon em sua enunciação. Ele poderia ter dito:

(3) "Eu almocei filé mignon, além de outras coisas." 
Todavia, acreditamos que, no contexto em que ocorreu a sentença em (2), a entoação seja suficiente para evidenciar que o complemento "além de outras coisas" é desnecessário. Isso é o que nos propusemos a verificar empiricamente nesta pesquisa.

Para que possamos investigar se há entoação particular para o foco não exaustivo, vamos comparar sua curva de $\mathrm{F}_{0}$ com as de sentenças com focos exaustivo e contrastivo, para averiguar se as curvas não se confundem.

Uma sentença com foco exaustivo, diferentemente de uma com foco não exaustivo, cancela quaisquer alternativas para a situação a que se refere. Uma asserção com esse tipo de foco automaticamente cancela outras alternativas para a afirmação que se faz (ELORDIETA E IRURTZUN, 2010). Por exemplo, na sentença abaixo (que responde à pergunta “Onde você estuda?"):

(4) “Eu estudo no COLÉGIO DE APLICAÇÃO."

temos foco exaustivo, pois o falante estuda em uma escola (essa informação é compartilhada pelos sujeitos do diálogo) e está informando qual é essa escola (e essa é informação nova, focalizada).

Já o foco contrastivo corrige uma asserção ou um pressuposto do interlocutor, uma afirmação prévia fornecida pelo ouvinte (MORAES, 2006)."O constituinte focalizado [...], além de veicular a informação que funciona como uma correção, apresenta um contraste em relação a outro constituinte" (QUAREZEMIN, 2009). Vejamos um exemplo. Um falante diz a outro:

(5) "Tu és filho do Pedro."

Se não for verdade que o ouvinte é filho do Pedro, então ele vai corrigir a afirmação, dizendo, por exemplo: 
(6) "Eu sou filho do JOÃO."

Nesse contexto, em (5) teríamos foco contrastivo, pois a sentença em questão corrige uma afirmação feita pelo interlocutor.

Assim, pretendemos investigar se a compreensão do foco não exaustivo e, por conseguinte, do exaustivo e do contrastivo, é de caráter puramente pragmático ou se a prosódia também tem papel preponderante nesse processo. Este é um tema ainda pouco explorado nos estudos linguísticos do português.

Para avaliar as curvas apresentadas por esses três tipos de foco, bem como observar semelhanças e diferenças entre eles, montamos um experimento de produção em que as situações gravadas eram adequadamente contextualizadas.

\section{Metodologia}

Assim, buscando investigar aquilo que identifica uma sentença como tendo foco não exaustivo, exaustivo ou contrastivo, montamos um experimento para coletar sentenças produzidas com os três tipos de foco nas quais se tem o mesmo conteúdo segmental (mesmas palavras), na modalidade declarativa, e na mesma ordem sintática.

Para essa coleta, quatro sujeitos ouviram, para cada sentença a ser produzida, três situações que contextualizavam, respectivamente, uma sentença com (a) foco não exaustivo, outra com (b) foco exaustivo e uma terceira com (c) foco contrastivo. Essa estratégia metodológica foi repetida quatro vezes (quatro sentenças), a partir da apresentação de situações que levavam o informante a produzir sentenças com os três tipos de foco. Isso resultou em 12 sentenças- quatro para cada tipo de foco (três) analisado. Por meio desse teste, foram produzidas e gravadas 48 sentenças (4sujeitos $\times 4$ situações $\times 3$ tipos de foco). 
Nesta análise, focalizamos falantes da região de Florianópolis, capital de Santa Catarina. As sentenças foram gravadas por dois homens e duas mulheres. Não se observaram diferenças significativas quando as produções foram analisadas separando-se o gênero dos informantes.

O padrão acentual das palavras focalizadas nas sentenças referia-se a núcleos oxítonos e paroxítonos (duas sentenças para cada tipo de acento). Não houve diferença na posição do pico relacionada ao tipo de acento da palavra. Mas houve diferença, sim, relacionada ao tipo de foco da sentença.

Neste corpus, os focos analisados encontram-se nas palavras que são complemento do verbo, situadas à periferia direita da sentença.

Abaixo, apresentamos, como exemplo da metodologia de coleta de dados, uma das sentenças utilizadas no experimento e as três histórias que foram criadas para dar o contexto em que o falante deveria produzir essa sentençacom cada tipo de foco:

(7) "O Kaká marcou um gol"

(a) Exemplo de história-contexto para foco não exaustivo:

Ontem teve jogo do Uruguai contra o Brasil. Ao chegar ao trabalho hoje, o Roberto me perguntou quantos gols foram marcados na partida. Eu só assisti ao primeiro tempo e vi o gol do Kaká, mas não sei se houve mais gols no segundo tempo. Então lhe disse:

- O Kaká marcou um gol.

(b) Exemplo de história-contexto para foco exaustivo:

Ontem teve jogo do Uruguai contra o Brasil. Ao chegar ao trabalho hoje, o Roberto me perguntou quantos gols o Kaká marcou. Eu, que assisti à partida inteira, lhe disse:

- O Kaká marcou um gol.

(c) Exemplo de história-contexto para foco contrastivo: 
Ontem teve jogo do Uruguai contra o Brasil. Ao chegar ao trabalho hoje, o Roberto me perguntou quantos gols foram marcados na partida, achando que o Kaká tinha marcado dois gols. Eu, que assisti à partida inteira, sei que o Kaká fez um gol, não dois. Então disse a ele:

- O Kaká marcou um gol.

As outras sentenças que compõem o corpus são:

(8) "O João come camarão."

(9) "O Pedro toma cerveja."

(10) "O Vítor ouve pagode."

Vejamos, na seção a seguir, os resultados obtidos a partir da análise dos dados.

\section{Análise das curvas e padrões entoacionais}

Com a análise das 48 sentenças que compõem o corpus da presente pesquisa, inicialmente tentamos verificar se a posição do acento nas palavras que compunham o núcleo entoacional das sentenças apresentava diferenças quanto aos tipos de foco investigados. Nessa primeira verificação, observamos que, de forma geral:

(a) Quando o foco era não exaustivo, o acento recaía predominantemente sobre a sílaba tônica, fosse ela paroxítona ou oxítona.

(b) Quando o foco era contrastivo, a sílaba prétônica recebia a maior parte dos acentos prosódicos, tanto nas palavras oxítonas quanto nas paroxítonas. Ouvindo as sentenças, percebemos ainda que a primeira sílaba das palavras (camarão, cerveja ou pagode) ou do sintagma nominal (um gol) que recebia o foco contrastivo era produzida com uma duração relativamente maior do que a duração das mesmas sílabas quando em sentenças com 
foco não exaustivo ou exaustivo. Creditamos esse fato ao caráter de correção próprio desse tipo de foco, pois o falante dá ênfase à palavra focalizada assim que começa a produzi-la, chamando a atenção do ouvinte para o contraste relacionado à palavra que está sendo corrigida.

(c) O pico das sentenças com foco exaustivo, por sua vez, dividiu-se de forma mais equilibrada, aparecendo ora na sílaba tônica ora na sílaba pré-tônica, igualmente distribuído.

A partir dessas observações, focalizando o contorno de $F_{0}$, foram identificadas curvas entoacionais que seriam prototípicas de cada tipo de foco. Identificamos, assim, duas curvas prototípicas para a não exaustividade, três curvas prototípicas para a exaustividade e duas para a contrastividade. Chegou-se a esses dados por meio da análise de todas as 48 curvas de $\mathrm{F}_{0}$ - as curvas foram extraídas com o auxílio do software Praat (BOERSMA e WEENINK). As sete curvas de $\mathrm{F}_{0}$ prototípicas são descritas a seguir, considerando seus pré-núcleos e núcleos entoacionais ${ }^{1}$.

Curva $\mathrm{A}$ (não exaustividade): a curva de $\mathrm{F}_{0}$ inicia alta, depois desce e mantém-se assim até a sílaba pré-tônica do núcleo, quando começa a subir na sílaba tônica, mantendo o pico no meio da sílaba tônica (acento circunflexo) com uma descida bastante abrupta ainda na sílaba tônica.

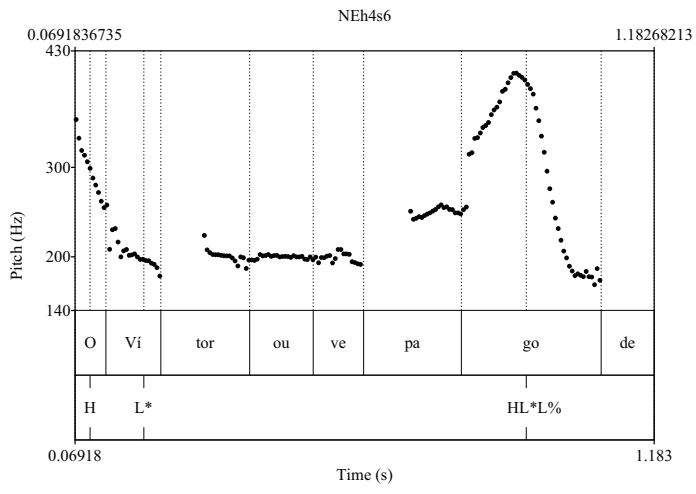

Fig.1 - Curva A, foco não exaustivo.

${ }^{1}$ Pré-núcleo é considerado a primeira sílaba acentuada do enunciado (no presente corpus, sempre o sujeito das sentenças), e o núcleo é visto como o movimento na última sílaba acentuada das sentenças (no sintagma nominal focalizado na sentença) e o tom de fronteira. 
Curva B (não exaustividade): a curva de $\mathrm{F}_{0}$ inicia baixa e mantém-se assim até a sílaba pré-tônica do núcleo, momento em que começa a subir, apresentando o pico na fronteira entre a sílaba pré-tônica e a tônica.

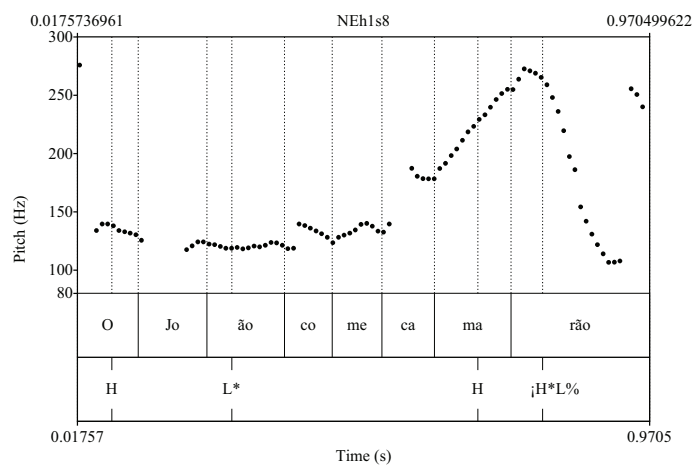

Fig. 2 - Curva B, foco não exaustivo.

Curva $\mathrm{C}$ (exaustividade): semelhante às curvas $\mathrm{A}$ ou B (do foco não exaustivo).

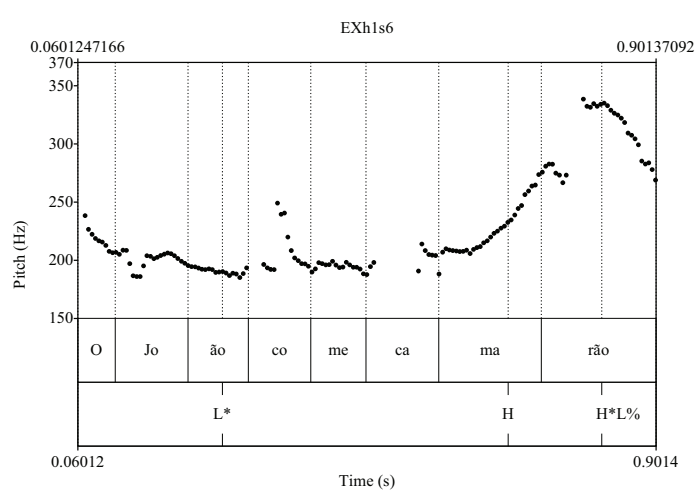

Fig. 3 - Curva C, foco exaustivo.

Curva D (exaustividade): apenas no pré-núcleo essa curva é semelhante às curvas $\mathrm{A}$ e $\mathrm{B}$ (do foco não exaustivo), pois, no núcleo, o pico está localizado na sílaba pré-tônica. 


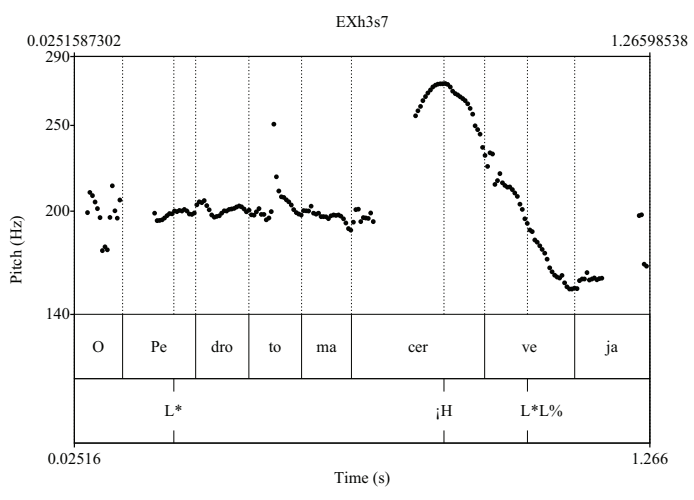

Fig. 4 - Curva D, foco exaustivo.

Curva E (exaustividade): apenas o núcleo é semelhante às curvas A e B (do foco não exaustivo), em que o maior movimento da curva de $\mathrm{F}_{0}$ acontece na sílaba tônica ou no limite entre a pré e a tônica No entanto, no pré-núcleo, há um movimento que evidencia acentualmente ora o verbo, ora o sujeito.

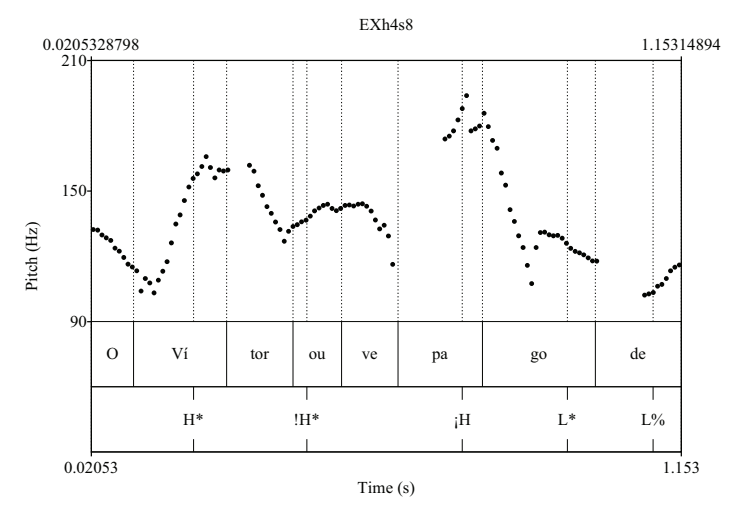

Fig. 5 - Curva E, foco exaustivo.

Curva $\mathrm{F}$ (contrastividade): semelhante às curvas $\mathrm{A}$ ou B (do foco não exaustivo). 


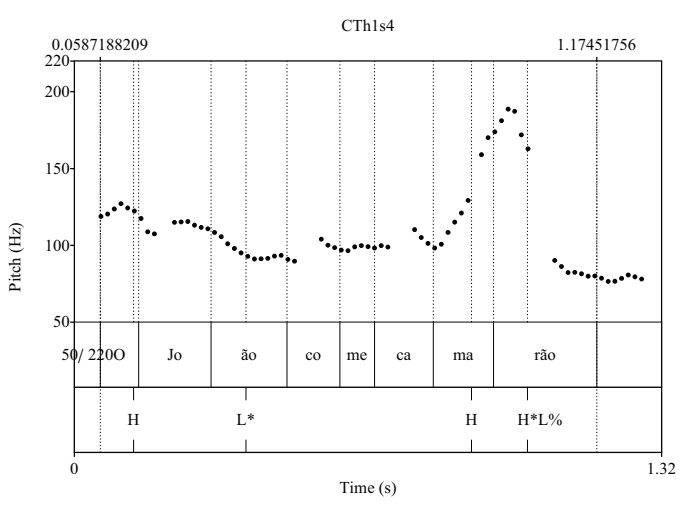

Fig. 6 - Curva F, foco contrastivo.

Curva $\mathrm{G}$ (contrastividade): semelhante às curvas D ou E (do foco exaustivo).

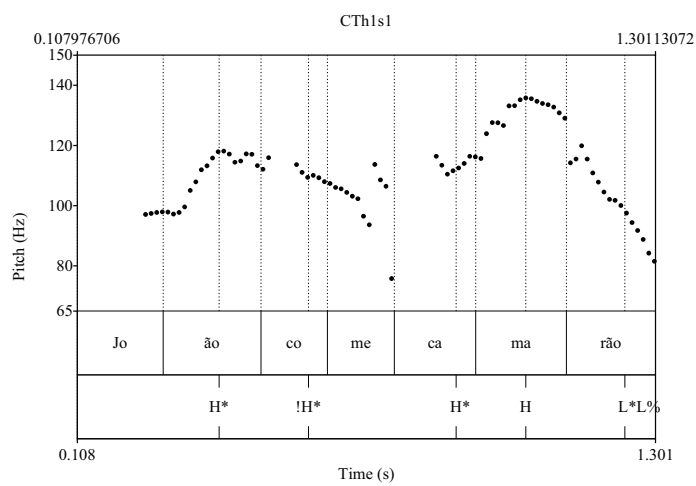

Fig. 7 - Curva G, foco contrastivo.

Após a identificação dos padrões entoacionais por meio da análise das curvas entoacionais das 48 sentenças (análise visual, comparando-se todas as curvas entoacionais e classificando os seus padrões), procedemos com a notação prosódica dessas produções, baseada na teoria métrica-autossegmental (PIERREHUMBERT, 1980), e analisamos os dados sob essa perspectiva teórica.

Os resultados mostraram que, de forma geral, todas as curvas apresentam um importante movimento descendente 
final com tom de fronteira L\%, semelhante aos contornos finais das declarativas. No entanto, diferentemente das declarativas neutras, essas curvas exibem um pitch range muito mais amplo, frequentemente chegando a uma oitava entre a pré-tônica e a tônica do núcleo.

$\mathrm{Na}$ análise detalhada dos dados, observamos separadamente o pré-núcleo, como dissemos anteriormente, considerando a primeira sílaba acentuada do enunciado (no presente corpus, sempre sujeito das sentenças), e o núcleo, visto como o movimento na última sílaba acentuada das sentenças (no sintagma nominal focalizado na sentença) e o tom de fronteira. Procedemos, então, com a análise dos percentuais de padrões observados na notação prosódica das 48 sentenças, como demonstra a Tabela 1 abaixo:

\begin{tabular}{|l|c|c|c|c|}
\hline \multirow{2}{*}{ FOCO } & \multicolumn{4}{|c|}{ ACENTO } \\
\cline { 2 - 5 } & \multicolumn{2}{|c|}{ Pré-núcleo } & \multicolumn{2}{c|}{ Núcleo } \\
\cline { 2 - 5 } & $\mathbf{L}^{\bullet}$ & $\mathbf{H}^{*}$ & $\mathbf{L}^{\bullet}$ & $\mathbf{H}^{*}$ \\
\hline Não exaustivo & $70 \%$ & $30 \%$ & $62 \%$ & $38 \%$ \\
\hline Exaustivo & $38 \%$ & $62 \%$ & $70 \%$ & $30 \%$ \\
\hline Contrastivo & $25 \%$ & $75 \%$ & $62 \%$ & $38 \%$ \\
\hline
\end{tabular}

Tabela 1: Percentuais de padrões acentuais do núcleo e do pré-núcleo das sentenças produzidas com focos não exaustivo, exaustivo e contrastivo.

Os dados mostraram dois padrões que ocorrem predominantemente. $\mathrm{O}$ primeiro, para sentenças com foco não exaustivo, apresenta o pré-núcleo baixo $\left(\mathrm{L}^{*}\right)$ e o núcleo ascendente-descendente, com o movimento concentrado na sílaba tônica $\left(\mathrm{H}^{*} \mathrm{~L} \%\right)$, como exemplificado na Fig.7. Esse resultado parece evidenciar que esse contorno identifica o foco não exaustivo, ratificando nossa hipótese de que o foco não exaustivo seria marcado pela prosódia, por meio de uma curva específica. 


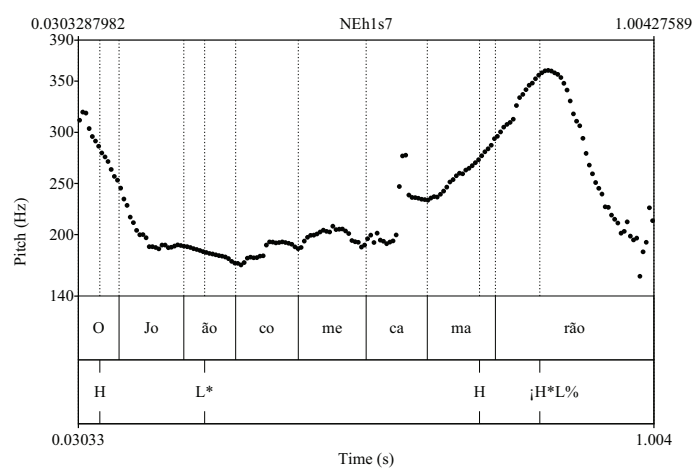

Fig. 8 - Padrão da curva entoacional de sentenças com foco não exaustivo.

O segundo padrão identificado neste experimento é o mesmo para sentenças com foco exaustivo ou com foco contrastivo. Esse padrão exibe um pré-núcleo alto $\left(\mathrm{H}^{*}\right)$ e um núcleo com uma sílaba pré-tônica com um tom muito alto $(\mathrm{H})$ em sua maioria, bem como um movimento descendente na sílaba tônica, com tom nuclear L*L\%, conforme ilustram a Fig.8 (foco exaustivo) e a Fig.9 (foco contrastivo).

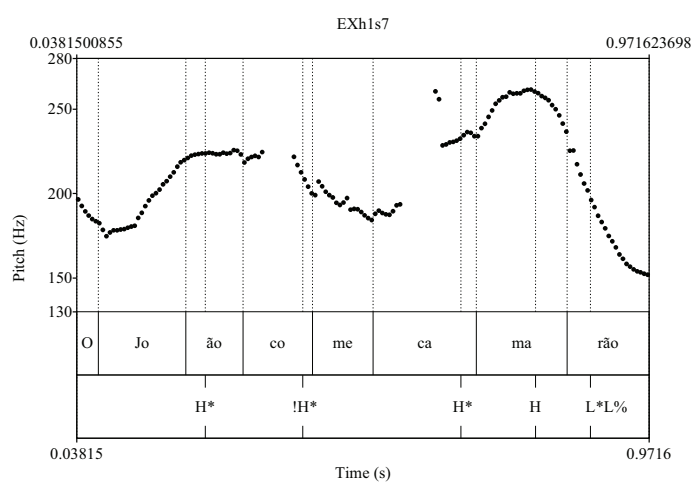

Fig. 9 - Padrão da curva entoacional de sentenças com foco exaustivo. 


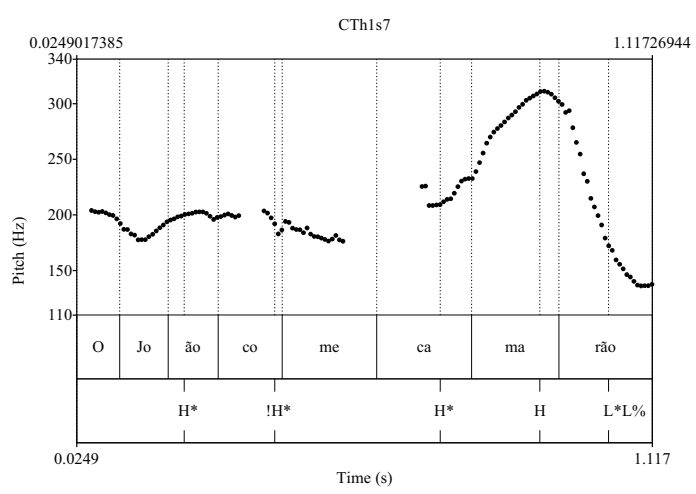

Fig. 10 - Padrão da curva entoacional de sentenças com foco contrastivo.

As sentenças com foco exaustivo ou foco contrastivo apresentaram curvas com características semelhantes, e parece ser o contexto que esclarece sobre o tipo de foco da sentença. A prosódia sozinha não demonstra ser suficiente para dar conta do tipo de foco e de informação da sentença. De fato, isso foi confirmado pelos informantes durante a realização do experimento.

Sentenças com foco exaustivo dependem de um marcador gramatical para se fazerem entender pelo ouvinte. Nossos testes mostraram que os informantes não se dão por satisfeitos com a própria produção, e dizem que, em uma situação real, eles usariam o marcador "só" para dar o sentido de exaustividade. Por exemplo:

(11) O João só come camarão (mais nada).

Sem poder usar o "só", os informantes da nossa pesquisa relataram a dificuldade em deixar clara a sua intenção de exaustividade. Pudemos perceber durante os testes que as sentenças exaustivas sem o uso do marcador "só" não pareciam adequadas àquele tipo de foco. Aconteceu de os informantes acabarem inserindo o "só" espontaneamente, tendo que reiniciar a gravação nesses casos. E eles reiteradamente nos disseram: "Não dá pra dizer sem o 'só'." 
O mesmo se deu com as sentenças de foco contrastivo, com a diferença que o marcador de que os informantes sentiram falta foi o "não". Eles queriam produzir:

(12) Não, o João come camarão.

Não podendo fazer isso, eles se sentiam insatisfeitos com as suas produções, dizendo que não seria assim que eles corrigiriam uma informação se fosse em um contexto real de fala. Dessa forma, aqui também nossa segunda pergunta parece respondida, confirmando a hipótese de que haveria a necessidade de um marcador lexical para os focos contrastivo e exaustivo ("não" e "só", respectivamente). Ou haveria outros parâmetros ainda não controlados que poderiam estar auxiliando na caracterização desses focos.

\section{Considerações finais}

Esses resultados vão, então, ao encontro das hipóteses levantadas, ou seja, para a identificação do foco não exaustivo, parece que apenas a curva entoacional já é suficiente. No caso de sentenças com foco exaustivo ou contrastivo, parece haver a necessidade de duas coisas para a sua identificação e diferenciação: o uso de itens lexicais e o contexto em que a sentença foi produzida.

Paralelamente, estamos dando andamento a testes de percepção para avaliarmos como o ouvinte identifica e classifica as sentenças que foram produzidas neste experimento. Acreditamos que os testes de percepção vão corroborar as primeiras conclusões apresentadas neste artigo.

Os experimentos aqui descritos fazem parte do projeto de pesquisa $O$ detalhe fonético: análise acústica exploratória de segmentos de fala, e foram aprovados pelo Comitê de Ética em Pesquisa com Seres Humanos (CEPSH) da Pró-Reitoria de Pesquisa e Extensão da Universidade Federal de Santa Catarina (UFSC), certificado número 2057. 


\section{Referências}

BOERSMA, Paul; WEENINK, David. Praat: doing phonetics by computer. Disponível em: <http://www.praat.org >.

CAGLIARI, Luiz Carlos. Da importância da prosódia na descrição de fatos gramaticais. In: ILARI, Rodolfo (Org.). Gramática do português falado. Campinas: Editora da Unicamp, 2002. p. 37-60.

ELORDIETA, Gorka; IRURTZUN, Aritz. The relationship between meaning and intonation in non-exhaustive answers: Evidence from Basque. 2010. Disponível em: <http://artxiker. ccsd.cnrs.fr/docs/00/64/52/07/PDF/Elordieta_Irurtzun_2010. pdf $>$. Acessado em: 10 jan. 2013.

FROTA, S. Prosody and Focus in European Portuguese: Phonological Phrasing and Intonation (Outstanding Dissertations in Linguistics). Nova York: Garlang Publishing, 2000.

GUNDEL, Jeanette K.; FRETHEIM, Thorstein. Topic and Focus. In: The handbook of pragmatics. HORN, Laurence R.; WARD, Gregory (Ed.). Australia: Blackweel, 2006.

KLEIN, S. Foco no português brasileiro. In: MÜLLER, Ana Lúcia; NEGRÃO, Esmeralda Vailati; FOLTRÃO, Maria José. (Org.) Semântica formal. São Paulo: Contexto, 2003.

LAMBRECHT, Knud. Information structure and sentence form: Topic, focus, and the mental representations of discourse referents. Cambridge: Cambridge University Press, 1994.

When subjects behave like objects: an analysis of the merging of $\mathrm{S}$ and $\mathrm{O}$ in sentence-focus constructions across languages. In: Studies in Language. v. 24, 2000, p. 611-682. Disponível em: <http://www.colorado.edu/ling/ courses/LAM7420/Lambrecht.pdf>, acesso em: 24 nov. 2013. 
MENUZZI, S. M. Algumas observações sobre foco, contraste e exaustividade. In: Revista Letras. n. 86. jul./ dez. 2012. Curitiba: Editora UFPR. p. 95-121. Disponível em: <http://ojs.c3sl.ufpr.br/ojs2/index.php/letras/article/ viewFile/29909/19907>. Acessado em: 2 mai. 2013.

MORAES, João Antônio de. Variações em torno de tema e rema. In: Cadernos do CNLF, vol. IX, no. 17, 2006, p. 279-289.

OLIVEIRA, Roberta Pires de; SEARA, Izabel Christine.

Semântica ou pragmática? um experimento em prosódia. In: CRUZ, Ronald Taveira da (Org.). As interfaces da gramática. Curitiba: Editora CRV, 2012. p.73-98.

PIERREHUMBERT, Janet. The phonology and phonetics of English intonation. Tese (Doutorado). Massachusetts: MIT Massachusetts Institute of Technology, 1980.

POLINSKY, Maria. Review article: Information structure and sentence form: Topic, focus, and the mental representations of discourse referents. By Knud Lambrecht. In: Language, v. 75, n. 3, set 1999, p. 567-582. Disponível em: <http://www.jstor. org/stable/417062>, acesso em: 23 nov. 2013.

QUAREZEMIN, Sandra. Estratégias de focalização no português brasileiro. Tese (Doutorado em Linguística). Florianópolis: Universidade Federal de Santa Catarina, 2009. $198 \mathrm{p}$.

. Foco e tópico nas línguas naturais. In: CRUZ, Ronald Taveira da (Org.). As interfaces da gramática. Curitiba: CRV, 2012. p. 99-117.

ROOTH, M. Focus. In: LAPPIN, Shalom (Ed.). The Handbook of Contemporary Semantic Theory. Oxford: Blackwell Publishers, 1997. p. 271-297.

[Recebido em 31 de agosto de 2013 e aceito para publicação em 05 de dezembro de 2013] 